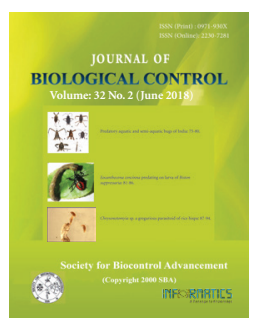

\title{
Host location and acceptance by parasitoid, Habrobracon hebetor and effect of varying Bacillus thuringiensis treatment against rice moth, Corcyra cephalonica
}

\author{
ISAAC L. MATHEW ${ }^{1}$, DEEPAK SINGH ${ }^{{ }^{*}}$ and C. P. M. TRIPATHI ${ }^{2}$ \\ ${ }^{1}$ Department of Zoology, St Andrew's College, Gorakhpur - 273001, Uttar Pradesh, India \\ ${ }^{2}$ Department of Zoology, Deen Dayal Upadhyay Gorakhpur University, Gorakhpur - 273009, Uttar Pradesh, India \\ ${ }^{*}$ Corresponding author E-mail: ceaesac@gmail.com
}

\begin{abstract}
The combined effect of microbial pesticide, Bacillus thuringiensis Berliner (Bt), and insect parasitoid, Habrobracon hebetor Say (Hymenoptera: Braconidae) was evaluated for the management of rice moth, Corcyra cephalonica (Stainton) (Lepidoptera: Pyralidae). This parasitoid is very useful in testing host-parasitoid interaction due to its high fecundity and short generation time. The host location and acceptance by parasitoid female, investigated by choice and no choice tests, showed marked preference towards later host instar larvae of C. cephalonica. Parasitoid induced mortality of Bt-intoxicated and Bt- reared host larvae was also investigated. C. cephalonica mortality was highest $(72.00 \pm 3.26 \%)$ and synergistic when host larvae were exposed to acute Bt treatment in conjunction with the parasitoid. A combined treatment of $\mathrm{Bt}$ with $H$. hebetor is an effective strategy in integrated pest control programmes of C. cephalonica and other stored grain pests.
\end{abstract}

KEY WORDS: Bacillus thuringiensis, Corcyra cephalonica, Combined treatment, Habrobracon hebetor, Pest management

(Article chronicle: Received: 22-03-2018; Revised: 28-05-2018; Accepted: 12-06-2018)

\section{INTRODUCTION}

Pests cause about a 40 per cent reduction in the world's crop yield (Mathew et al., 2014). In tropical countries insect pests cause heavy food grain losses in storage, particularly at the farm level, ranging from approximate $10 \%$ of the production in India to about $25-40 \%$ in Sub-Saharan Africa (Kangade, 2012). Corcyra cephalonica (Stainton) (Lepidoptera: Pyralidae), the rice moth, is a common notorious pest in tropical and sub-tropical regions of the world infesting stored cereals and cereal commodities. The larvae feed on a variety of stored cereals such as wheat, rice, sorghum, maize, millet, etc., causing serious damage (Verma and Pathak, 2018). It also feeds on a broad range of commodities, including dried vegetable materials and dried fruits like almonds, date palm, nuts, chocolates, biscuits, oilcakes, etc. (Kangade, 2012). High levels of food grain loss can be attributed to inadequate post-harvest management practices and poorly designed storage structures leading to conditions suitable for pest infestation (Anon, 1989). The goal of increasing food availability cannot be achieved without proper management of pest.

The harmful effect of chemical pesticides on nontarget organisms is a reality and in South Asia, the use of chemical pesticides in agriculture has seen a sharp increase in recent years particularly in India (Anon, 2005).
In the past decades, the indiscriminate use of chemical pesticides has steadily increased (David, 1995; Ranga et al., 2007) resulting in unintended effects such as, natural hazards (Pimentel, 1996), development of insect pest resistance (Georghiou, 2012), pest resurgence (Yu et al., 2008), outbreak of the secondary pest (Dutcher, 2007) reduction in species diversity (Wilby and Thomas, 2002) alteration of decomposition of organic material and nutrient cycling (Edward, 1980) and objectionable pesticide residue (Metcalf, 1994). Although chemical control is still recognized as an important strategy in an IPM program, the success of any such program along with biological control depends on their judicious integration (Wright and Verkert, 1995; Zhao, 2000; Mahdavi, 2013). Integrating biocontrol agents in this scenario requires sufficient deep knowledge and impact assessment of the pesticide on natural enemies (Croft, 1990). Chemical control, if at all integrated, should be least disruptive to biocontrol agents and should be used only when it is necessary (Mahdavi, 2013).

Habrobracon hebetor Say, 1836, (Hymenoptera: Braconidae), is a gregarious, cosmopolitan ectoparasitoid of the larval stage of stored-grain pyralid moths (Lepidoptera: Pyralidae) such as C. cephalonica (Singh et al., 2009). This ectoparasitoid has high reproductive rate, short generation time and a large number of host species; hence it is preferred by most researchers for host-parasitoid interactions 
studies (Gündüz and Gülel, 2005; Singh et al., 2014; Singh et al., 2016). Moreover being a potential biocontrol agent, it has been effectively used in the control of stored product moths (Yu et al., 2003). The females of H. hebetor prefer to attack and lay variable numbers of eggs on or near the surface of paralyzed last (fifth) instar host larvae (Antolin et al., 1995; Ghimire and Phillips, 2014). It exhibits high fecundity and natural rate of increase, which makes it a promising agent for use against $C$. cephalonica, a very common stored grain pest (Singh et al., 2016).

Combining more than one method of biological control for pest management can be a more efficient strategy. Bacillus thuringiensis Berliner (Bt), a Gram-positive, sporeforming soil bacteria, has not only emerged as the major ecofriendly biopesticide against major pests but also a key source of genes for developing transgenic crops expressing -endotoxins to provide pest resistance (Singh and Mathew, 2015). Bt is a member of the $B c$ (Bacillus cereus) group and has emerged as the most successful microbial pesticide having great potential in IPM programmes (Blumberg et al., 1997; Singh and Mathew, 2015). Strategies involving the combination of $B t$ and a natural enemy has shown varying effects of $B t$ on pest and its natural enemies. Integrating $B$. thuringiensis with a parasitoid has shown satisfactory control of lepidopterous pests (Blumberg et al., 1997). Bt has been shown to have no adverse effects on parasitoid development or its emergence when used against pest populations (Weseloh and Andreadis, 1982; Ulpah and Kok, 1996; Oluwafemi et al., 2009). Surgeoner and Farkas (1990) have recommended the use of $B t$ insecticide, such as Dipel, for use in integrated pest management programs and they have also shwed that it is harmless to most of the beneficials tested. Oluwafemi et al. (2009) have reported that a combination of $B t$ with $H$. hebetor as a biological control agent, resulted in successful control of Plodia interpunctella population and has recommended the use of $B t$ in combination with a parasitoid for the control of other lepidopteran pests. However, Erb et al., (2001) reported that Bt can adversely affect certain parasitoids by causing enhanced or decreased parasitoid larval development times and altered parasitoid sex ratios (Erb et al. 2001). Due to premature host death it could reduce the parasitism (Vail et al., 1972), decreased parasitoid survival (Nealis and van Frankenhuyzen, 1990) and lower parasitoid emergence rates (Atwood et al., 1997).

Several experimental data are available on the capacity of parasitoids to search, attack and successfully develop on different stages of the same host (Canale and Loni, 2006, Akinkurolere et al., 2009). While foraging parasitoids may encounter different host developmental stages which are vulnerable to attack, these hosts may differ in their profitability in terms of fitness, so parasitoid becomes selective for particular stages of their hosts (Godfray and Hunter, 1994). In this study, we aim to assess the outcome and predictive accuracy by choice and no choice test in laboratory condition to improve the method and interpretation of host specificity of $H$. hebetor and the suitability of using $B t-$ parasitoid combination for the control of C. cephalonica.

\section{MATERIAL AND METHODS}

All the insect cultures were maintained (Singh, 2004) and the assays and experiments were conducted at $27 \pm 2^{\circ} \mathrm{C}$, $70 \pm 10 \% \mathrm{RH}$ and 12:12 L:D photoperiod.

\section{Rearing of the pest}

To maintain the culture of Corcyra cephalonica, the eggs of rice moth were obtained from the Central Integrated Pest Management Centre, Gorakhpur (CIPMC, GKP) and kept with coarsely ground mixed grain diet in specially designed large plastic containers of size $45 \mathrm{~cm} \times 25 \mathrm{~cm} \times 15 \mathrm{~cm}$. The containers were observed daily for the hatching of the eggs and the diet was replenished regularly after consumption and damage by the larvae. After 3-4 generations, fullgrown larvae of rice moth from this culture were taken to feed and rear the parasitoid Habrobracon hebetor (Singh et al., 2015; Singh et al., 2016). Larvae were also reared in mixed grain diets with $\mathrm{Bt}$ at $\mathrm{LC}_{10}$ and $\mathrm{LC}_{25}$. These larvae were used in mortality experiments.

\section{Rearing of the parasitoid}

For the culture of Habrobracon hebetor, adults were collected from the CIPMC, GKP. Male and female insect were paired in a beaker $(250 \mathrm{ml})$ having 10 full grown $5^{\text {th }}$ instar larvae of Corcyra cephalonica, covered with a fine muslin cloth (Singh et al., 2015; Singh et al., 2016). After the third generation, adults were utilized in experiments.

\section{Bacillus thuringiensis}

Commercial formulation based on B. thuringiensis selected for the assays was Dipel DF (B. thuringiensis var. kurstaki, strain ABTS-351, $32 \mathrm{MIU} \mathrm{g}^{-1}$ [millions of International Units per gram] from Valent Biosciences Corporation, USA.

\section{Preliminary assay of $\mathbf{L C}_{\mathbf{5 0}}$}

Bioassay of Bt on Corcyra cephalonica was carried out as per Oluwafemi et al. (2009). Dipel DF was serially diluted using 1, 2, 4, 8, 16, 32 and $64 \mathrm{mg}$ per $\mathrm{mL}$ of distilled water. $1 \mathrm{~mL}$ distilled water served as control. The dilutions were incorporated into artificial diet @ $0.2 \mathrm{~mL} / \mathrm{g}$ and al- 
lowed to dry. The treated diets were transferred into $250 \mathrm{~mL}$ Borosil glass beakers @ $10 \mathrm{~g} /$ beaker. Twenty C. cephalonica $4^{\text {th }}$ instar larvae were introduced into each beaker and maintained in the laboratory. Larval mortality was recorded after 24, 48 and $72 \mathrm{~h}$ of initial inoculation. The experiment was replicated five times. $\mathrm{LC}_{50}$ for $48 \mathrm{~h}$ was used in further experiments (Oluwafemi et al., 2009). Also, $\mathrm{LC}_{25}$ and $\mathrm{LC}_{10}$ for $48 \mathrm{~h}$ were used to prepare $B t$ treated diets to rear host larvae for mortality experiments.

\section{Host location and acceptance by parasitoid female}

Choice and no-choice tests were utilized to determine the preferences of the parasitoid in host location and acceptance (Oluwafemi et al., 2009).

\section{Choice test}

Ten C. cephalonica larvae, two of each instar (I to V), reared on a mixed diet, were placed in a $500 \mathrm{~mL}$ beaker covered with a muslin cloth. A control, without parasitoid, was also set up. All experiments including control were replicated 20 times. Larval mortality was observed after $8 \mathrm{~h}$ of introducing gravid female $H$. hebetor.

\section{No choice test}

Ten first instar larvae of $C$. cephalonica which were reared on a mixed diet, were placed in a $500 \mathrm{~mL}$ beaker covered with muslin cloth. The same protocol was followed for $2^{\text {nd }}, 3^{\text {rd }}, 4^{\text {th }}$ and $5^{\text {th }}$ host-instars. Controls were also set up. All treatments were replicated 20 times. Larval mortality was observed after $8 \mathrm{~h}$ of introducing gravid female $H$. hebetor.

\section{Effect of Combining Bt and Parasitoid on Corcyra Ceph- alonica}

In this experiment, there were six treatments with each bioassay being carried out using ten $C$. cephalonica larvae of $4^{\text {th }}$ instar in $500 \mathrm{~mL}$ beakers with $10 \mathrm{~g}$ diet in 5 replicates each. It was covered with a muslin cloth. Varying treatments of $\mathrm{Bt}$ and parasitoid were:

Untreated (control): Corcyra cephalonica larvae were placed with untreated mixed grain diet.

Bt treatment: Corcyra cephalonica larvae were placed with $\mathrm{Bt}$ treated mixed grain diet at $\mathrm{LC}_{50}$.

Parasitoid treatment: Corcyra. cephalonica larvae were placed with untreated mixed grain diet then after 4 hours exposed to gravid female parasitoid for $24 \mathrm{~h}$.
Bt-parasitoid combined treatment: Corcyra cephalonica larvae were placed with $\mathrm{Bt}$ treated mixed grain diet at $\mathrm{LC}_{50}$ then after $4 \mathrm{~h}$ exposed to gravid female parasitoid for $24 \mathrm{~h}$.

Bt $\mathrm{LC}_{10}$ reared larvae-parasitoid combined treat-

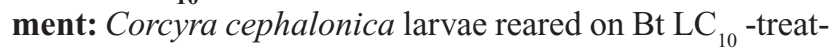
ed mixed diet were placed in the same diet and then after 4 hours exposed to gravid female parasitoid for $24 \mathrm{~h}$.

Bt $\mathrm{LC}_{25}$ reared larvae-parasitoid combined treat-

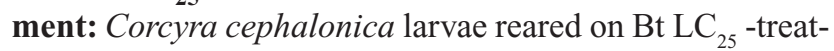
ed mixed diet were placed in the same diet and then after 4 hours exposed to gravid female parasitoid for $24 \mathrm{~h}$.

The experiments were observed after $24 \mathrm{~h}$ for the number of larval mortality/parasitization (Oluwafemi et al., 2009).

\section{Statistical analysis}

Data from choice and no choice tests were corrected for that of control using Abbott's Formula: Corrected mortality $(\%)=\left(\mathrm{P}-\mathrm{P}_{0}\right) /\left(100 \mathrm{P}_{0}\right) \times 100$, where $\mathrm{P}$ is the percent mortality of treated insects, $\mathrm{P}_{0}$ is the percent mortality of insects in the untreated control (Abbott 1925).

The $\mathrm{LC}_{50}$ and other $\mathrm{LC}$ values for 24,48 and $72 \mathrm{~h}$ (with 95\% confidence limits) were calculated by using POLO Plus 2.0 program (Leora Software, 2005) and Probit Analysis Statistical Method and mortality data of preliminary screening tests and different treatments were subjected to analysis of variance (One Way ANOVA) and mean separation tests were conducted with Tukey's HSD using SPSS Statistics version 20.0 (SPSS Inc., Chicago, IL, USA) statistical analysis software.

\section{RESULTS AND DISCUSSION}

The $\mathrm{LC}_{50}$ value (with $95 \%$ confidence limits) of $\mathrm{Bt}$ on C. cephalonica 4 th instar larvae for 24,48 and $72 \mathrm{~h}$ were 65.813 (52.946 - 85.689), 36.311 (29.953 - 45.704) and $17.745(15.350-20.742) \mathrm{mg} / \mathrm{mL}$ respectively.

\section{Choice test}

In Choice test, the mean percent mortality $( \pm$ Standard Error) of $1^{\text {st }}, 2^{\text {nd }}, 3^{\text {rd }}, 4^{\text {th }}$ and $5^{\text {th }}$ instar larvae of C. cephalonica due to parasitoid H. hebetor were $5.00 \pm 3.44,10.00$ $\pm 4.59,45.00 \pm 6.18,65.00 \pm 5.26$ and $85.00 \pm 5.25$ respectively (Fig. 1). 


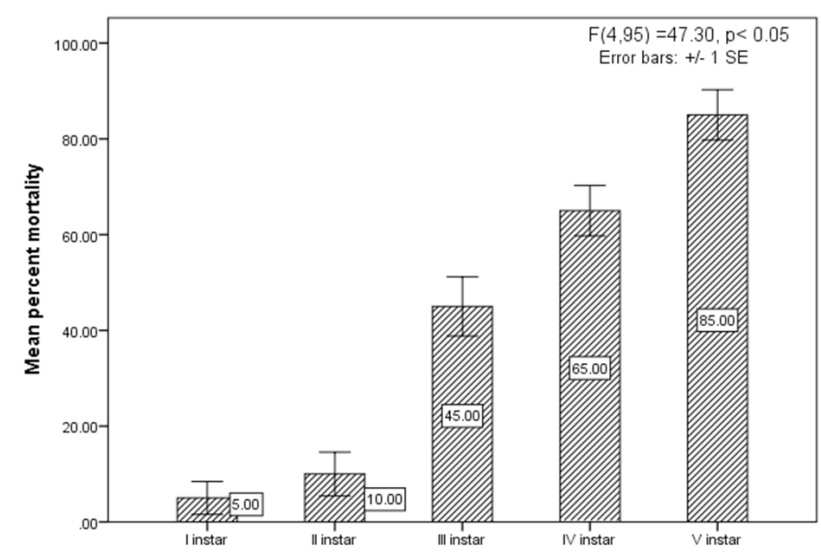

Fig. 1. Mean percent mortality of Corcyra cephalonica larvae in Choice test.

One-way Analysis of Variance (ANOVA) yielded statistically significant difference between the mortality of all instar larvae of C. cephalonica $\left(\mathrm{F}_{(4,95)}=47.302, \mathrm{p}<.05\right)$ (Table 1). Tukey Post Hoc Test for multiple comparisons revealed statistically significant difference between the mortality of $1^{\text {st }}$ instar $(5.00 \pm 3.44, \mathrm{p}<.05)$ when compared to $3^{\text {rd }}$ instar $(45.00 \pm 6.18, \mathrm{p}<.05), 4^{\text {th }}$ instar $(65.00$ $\pm 5.26, \mathrm{p}<.05)$ and $5^{\text {th }}$ instar $(85.00 \pm 5.25, \mathrm{p}<.05)$ larvae. Similarly, statistically significant difference was seen between the mortality of $2^{\text {nd }}$ instar $(10.00 \pm 4.59, \mathrm{p}<.05)$ when compared to that of $3^{\text {rd }}, 4^{\text {th }}$ and $5^{\text {th }}$ instar larvae. But there was no statistically significant difference between the mortality of $1^{\text {st }}$ instar $(5.00 \pm 3.44, \mathrm{p}=.955)$ and $2^{\text {nd }}$ instar larvae $(10.00 \pm 4.59, \mathrm{p}=.955)$.

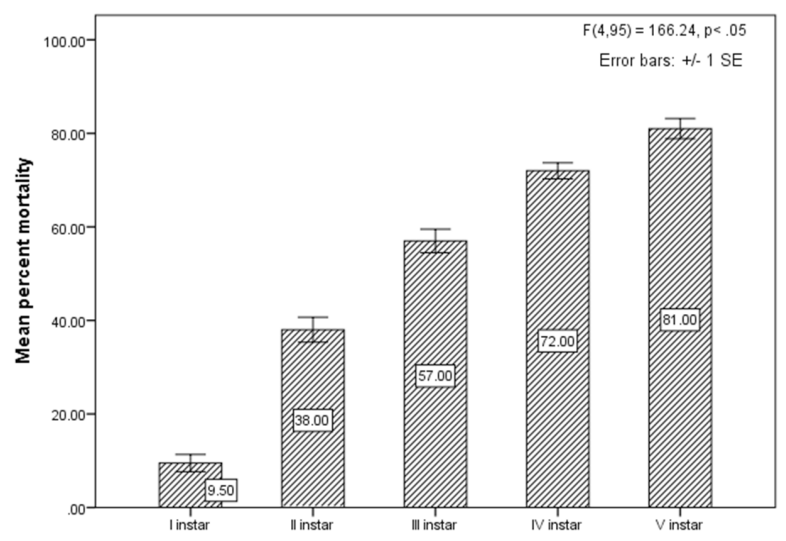

Fig. 2. Mean percent mortality of Corcyra cephalonica larvae in No Choice test.
The parasitoid was provided the opportunity to parasitize any out of the five host larvae instars. The lowest mortality was recorded in $1^{\text {st }}$ and $2^{\text {nd }}$ instars. Whereas, the highest mortality was recorded in $5^{\text {th }}$ instar larvae. H. hebetor shows preference towards larger sized instars for laying eggs.

\section{No Choice Test}

In No Choice test the mean percent mortality ( \pm Standard Error) of $1^{\text {st }}, 2^{\text {nd }}, 3^{\text {rd }}, 4^{\text {th }}$ and $5^{\text {th }}$ instar larvae of C. cephalonica due to parasitoid $H$. hebetor were $9.50 \pm 1.85,38.00$ $\pm 2.67,57.00 \pm 2.52,72.00 \pm 1.72$ and $81.00 \pm 2.16$ respectively (Fig. 2).

One-way Analysis of Variance (ANOVA) yielded statistically significant difference between the mortality of all instar larvae of $C$. cephalonica $\left(\mathrm{F}_{(4,95)}=78.536, \mathrm{p}<.05\right)$ (Table 1). Tukey Post Hoc Test for multiple comparisons revealed statistically significant difference between the mortality among $1^{\text {st }}$ instar $(9.50 \pm 1.85, \mathrm{p}<.05), 2^{\text {nd }}$ instar $(38.00$ $\pm 2.67, \mathrm{p}<.05), 3^{\text {rd }}$ instar $(57.00 \pm 2.52, \mathrm{p}<.05), 4^{\text {th }}$ instar $(72.00 \pm 1.72, \mathrm{p}<.05)$ and $5^{\text {th }}$ instar $(81.00 \pm 2.16, \mathrm{p}<.05)$ C. cephalonica larvae.

$H$. hebetor showed significantly increasing parasitization of $3^{\text {rd }}, 4^{\text {th }}$ and $5^{\text {th }}$ instar host larvae. $5^{\text {th }}$ instar larvae being less active and motile is the easiest target. H. hebetor shows preference towards larger sized instars for laying eggs.

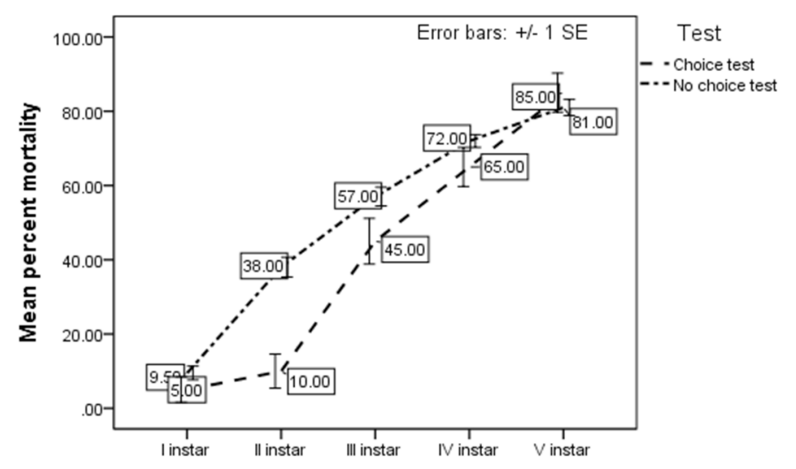

Fig. 3. Compared mean percent mortality of Corcyra cephalonica larvae in Choice and No Choice test. 
Table 1. Percentage mortality of Corcyra cephalonica larval instars by Habrobracon hebetor under no-choice and choice conditions. Mortality is expressed as percentage mean $\pm \mathrm{SE}$

\begin{tabular}{|c|c|c|c|c|}
\hline \multirow{2}{*}{ Instar larvae } & \multicolumn{2}{|c|}{ No-choice test } & \multicolumn{2}{c|}{ Choice test } \\
\cline { 2 - 5 } & Control & Treatment & Control & Treatment \\
\hline $1^{\text {st }}$ & $2.00 \pm 1.26 \mathrm{a}$ & $9.50 \pm 1.85 \mathrm{a}$ & $2.50 \pm 1.45 \mathrm{a}$ & $5.00 \pm 3.44 \mathrm{a}$ \\
\hline $2^{\text {nd }}$ & $0.00 \pm 0.00 \mathrm{a}$ & $38.00 \pm 2.67 \mathrm{~b}$ & $0.00 \pm 0.00 \mathrm{a}$ & $10.00 \pm 4.59 \mathrm{a}$ \\
\hline $3^{\text {rd }}$ & $0.00 \pm 0.00 \mathrm{a}$ & $57.00 \pm 2.52 \mathrm{c}$ & $0.00 \pm 0.00 \mathrm{a}$ & $45.00 \pm 6.18 \mathrm{~b}$ \\
\hline $4^{\text {th }}$ & $0.00 \pm 0.00 \mathrm{a}$ & $72.00 \pm 1.72 \mathrm{~d}$ & $0.00 \pm 0.00 \mathrm{a}$ & $65.00 \pm 5.26 \mathrm{c}$ \\
\hline $5^{\text {th }}$ & $0.00 \pm 0.00 \mathrm{a}$ & $81.00 \pm 2.16 \mathrm{e}$ & $0.00 \pm 0.00 \mathrm{a}$ & $85.00 \pm 5.25 \mathrm{~d}$ \\
\hline
\end{tabular}

Means followed by different letters in each column are significantly different $(P<0.05)$ using Tukey's B test

Table 2. Percentage mortality of Corcyra cephalonica ( $4^{\text {th }}$ instar larvae) after exposure to $B t$, parasitoid and $B t-$ parasitoid combined treatments

\begin{tabular}{|l|c|c|}
\hline \multicolumn{1}{|c|}{ Treatments } & Mortality \pm SE & Confidence Limits \\
\hline Control & $0.00 \pm 0.00 \mathrm{a}$ & $0.00-0.00$ \\
\hline$B t$ & $23.00 \pm 2.13 \mathrm{~b}$ & $18.17-27.83$ \\
\hline $\mathrm{P}$ & $35.00 \pm 2.69 \mathrm{c}$ & $28.92-41.08$ \\
\hline$B t-\mathrm{P}$ (host larvae exposed 4hrs in $\left.\mathrm{LC}_{50}\right)$ & $72.00 \pm 3.26 \mathrm{~d}$ & $64.61-79.39$ \\
\hline$B t-\mathrm{P}$ (host larvae reared on $\mathrm{LC}_{10}$ diet) & $67.00 \pm 2.13 \mathrm{~d}$ & $62.17-71.83$ \\
\hline$B t-\mathrm{P}$ (host larvae reared on $\mathrm{LC}_{25}$ diet) & $65.00 \pm 3.42 \mathrm{~d}$ & $57.27-50.85$ \\
\hline
\end{tabular}

Means followed by different letters in each column are significantly different $(P<0.05)$ using Tukey's B test. (Control=clean untreated $\operatorname{diet} ; B t=$ diet treated with $B t$ at $\mathrm{LC}_{50}$ dose; $\mathrm{P}=$ parasitoid (Habrobracon hebetor); $B t-\mathrm{P}=B t$-parasitoid (combined treatment). $B t=$ Bacillus thuringiensis.

\section{Effect of Combining $B t$ and Habrobracon hebetor against Corcyra Cephalonica}

Significantly high mortality rates were observed in all $B t$, parasitoid and Bt-Parasitoid treatments (Table 2). Oneway Analysis of Variance (ANOVA) yielded statistically significant difference between the $C$. cephalonica mortality among treatments $\left(\mathrm{F}_{(5,54)}=130.697, \mathrm{p}<.05\right)$. Tukey Post Hoc Test for multiple comparisons revealed statistically significant difference between the mortality in control experiment $(0.00 \pm 0.00, \mathrm{p}<.05)$ when compared to that in treatments of $\mathrm{Bt}(23.00 \pm 2.13, \mathrm{p}<.05)$, parasitoid $(35.00 \pm 2.69, \mathrm{p}<.05), \mathrm{Bt}-\mathrm{P}$ (larvae exposed $4 \mathrm{hrs}$ in $\left.\mathrm{LC}_{50}\right)$ $(72.00 \pm 3.26, \mathrm{p}<.05), B t-\mathrm{P}$ (larvae reared on $\mathrm{LC}_{10}$ diet) $(67.00 \pm 2.13, \mathrm{p}<.05)$ and $B t-\mathrm{P}\left(\right.$ larvae reared on $\mathrm{LC}_{25}$ diet $)$ $(65.00 \pm 3.42, \mathrm{p}<.05)$.

Highest larval host mortality was observed in $B t-\mathrm{P}$ (larvae exposed $4 \mathrm{hrs}$ in $\mathrm{LC}_{50}$ ) combination and there was no statistically significant difference between it (72.00 \pm $3.26, \mathrm{p}=.169$ ) and the $B t-\mathrm{P}$ (larvae reared on $\mathrm{LC}_{10}$ diet) $(67.00 \pm 2.13, \mathrm{p}=.169)$ and $B t-\mathrm{P}$ (larvae reared on $\mathrm{LC}_{25}$ diet) $(65.00 \pm 3.42, \mathrm{p}=.056)$ treatments. Similarly there was no statistically significant difference between larval mortality in $B t-\mathrm{P}$ (larvae reared on $\mathrm{LC}_{10}$ diet) (67.00 \pm $2.13, \mathrm{p}=.580$ ) and $B t-\mathrm{P}$ (larvae reared on $\mathrm{LC}_{25}$ diet) treatments.

The present experiments show that Habrobracon hebetor has the capacity to locate and parasitize all stages of Corcyra cephalonica but it showed specific preference for $4^{\text {th }}$ and $5^{\text {th }}$ instar larvae when compared with all other stages. Early instars are generally difficult to locate as the food media serves as a refuge. The results are in accordance with the studies done by Sait et al. (1997); they showed that it is strenuous for the parasitoid Venturia canescens to search and parasitize Plodia interpunctella $2^{\text {nd }}$ instar larvae which are concealed in refuge than $5^{\text {th }}$ instar within the same environment (Akinkurolere et al., 2009). Our studies reveal that the choice test, host location, and parasitism by $H$. hebetor is negligible and non-significant in early stages (instars). Ode et al. (1997) proved that $H$. hebetor can withhold or reduce the number of eggs laid if there are poor quality hosts or non preferred stages. In another study conducted by Akinkurolere et al. (2009) it was shown that early instar larvae are active and can push itself deep into the treated 
diet during feeding in contrast to high instar larvae that tend to move away from the infested diet to the surface for pupation sites (Akinkurolere et al., 2009).

In no-choice test the study indicated higher interaction with the later stages $\left(3^{\text {rd }}\right.$ to $\left.5^{\text {th }}\right)$, again the Ist and $2^{\text {nd }}$ stages are not preferred. $2^{\text {nd }}$ stage, however, showed some acceptance with the no choice test but the best suitable was again the $5^{\text {th }}$ instar. The inability of $H$. hebetor to locate an attack early instar in comparison to later instars could result from the weaker vibration produced by early instars (Akinkurolere et al., 2009). The low preference in this study of early instars is due to age-dependent mechanisms which parasitoids used to discriminate between different instars of the same host (Mattiacci and Dicke, 1995a) and also less time and energy is expended while searching the later instars instead of early instars. Therefore, later instars could be easily located and attacked and is more profitable to the parasitoid in a population of mixed age group of host instars (Mattiacci and Dicke, 1995b; Akinkurolere et al., 2009). In no-choice test, only the physiological host range can be estimated (Withers and Browne, 2004) so the ability to predict the ecological host ranges of parasitoid by laboratory-based host specificity tests alone has its limitations. A more accurate prediction of ecological host range can be done by choice test (Murray, 2010). Babendreier et al. (2005) reported that there is generally an agreement between no choice and choice test result in most insect control studies that have included both (Table 1). The results obtained in this study conformed to the same view (Fig. 3).

Habrobracon hebetor is an effective biocontrol agent especially against host population that wanders and feed on the surface (Akinkurolere et al., 2009). Although it parasitizes all instars, it is more effective on later instars, which are more profitable to the parasitoid as less time and energy it wasted to locate and parasitize. H. hebetor is a good biocontrol agent against Corcyra cephalonica (Deepak et al., 2006; Singh et al., 2016). In this study, the result demonstrated that a combined treatment of $B t$ and $H$. hebetor against $C$. cephalonica was more effective and lethal than both $B t$ and $H$. hebetor when used alone, thus suggesting a synergistic effect. $B t$ being more lethal in early instar $\left(1^{\text {st }}\right.$ and $\left.2^{\text {nd }}\right)$, the $3^{\text {rd }}$ to $5^{\text {th }}$ instars are more profitable for $H$. hebetor with $5^{\text {th }}$ instar recording the highest mortality. These results were same as observed by Zhang et al. (1995). The combined treatment was significantly more effective and $B t$ did not prevent parasitoid development and reproducibility, which suggests that their lethal effect enhanced when combined together.
The study suggests that Habrobracon hebetor prefer later host instars as far as locating the host and parasitization is concerned, and combining $B t$ with $H$. hebetor as biocontrol agent results in a high reduction of Corcyra cephalonica population. Bt can, therefore, be used along with $H$. hebetor in combined treatment against $C$. cephalonica and other lepidopteran pests. Further studies on the interference of $B t$ with reproduction and development of $H$. hebetor is needed to correctly assess and utilize the full potential of such combined treatment for pest control.

\section{ACKNOWLEDGMENT}

The authors thank Prof. J.K. Lal, Secretary and Principal, St. Andrew's College, Gorakhpur, for his constant encouragement and providing laboratory and library facilities.

\section{REFERENCES}

Abbott WS. 1925. A method of computing the effectiveness of an insecticide. $J$ Econ Entomol. 18(2): 265-267. https://doi.org/10.1093/jee/18.2.265a

Akinkurolere RO, Boyer S, Chen H, Zhang H. 2009. Parasitism and host-location preference in Habrobracon hebetor (Hymenoptera: Braconidae): role of refuge, choice, and host instar. $J$ Econ Entomol. 102(2): 610-615. https://doi.org/10.1603/029.102.0219 PMid:19455754

Anon, 1989. Implementation Phase of the Project. 2nd Annu Rep (ICIPE/UNECA, Mar 1988 - Feb 1989).

Anon, 2005. Excess use of chemical pesticides causing huge damage to ecology in coastal Andhra Pradesh. Business Standard 12: 1.

Antolin MF, Ode PJ, Strand MR. 1995. Variable sex ratios and ovicide in an outbreeding parasitic wasp. Anim Behav. 49(3): 589-600. https://doi.org/10.1016/00033472(95)80192-8

Atwood DW, Young III, SY, Kring TJ. 1997. Development of Cotesia marginiventris (Hymenoptera: Braconidae) in tobacco budworm (Lepidoptera: Noctuidae) larvae treated with Bacillus thuringiensis and Thiodicarb. $J$ Econ Entomol. 90(3): 751-756. https://doi.org/10.1093/ jee/90.3.751

Babendreier D, Bigler F, Kuhlmann U. 2005. Methods used to assess non-target effects of invertebrate biological control agents of arthropod pests. BioControl 
50(6): 821-870. https://doi.org/10.1007/s10526-005$3633-3$

Blumberg D, Navon A, Keren S, Goldenberg S, Ferkovich SM. 1997. Interactions among Helicoverpa armigera (Lepidoptera: Noctuidae), its larval endoparasitoid Microplitis croceipes (Hymenoptera: Braconidae), and Bacillus thuringiensis. J Econ Entomol. 90(5): 1181-1186. https://doi.org/10.1093/jee/90.5.1181

Canale A, Loni A. 2006. Host location and acceptance in Psyttalia concolor: Role of host instar. B INSECTOL. 59(1): 7.

David BV. 1995. 'Indian pesticide industry and overview'. Kotharis Desk Book series. pp. 16-36.

Deepak S, Singh RP, Tripathi CPM. 2006. Effect of host diet on life table statistics of Bracon hebetor Say (Hymenoptera: Braconidae). J Biol Control 20(2): 165-168.

Dutcher JD. 2007. A Review of Resurgence and Replacement Causing Pest Outbreaks in IPM. pp. 27-43. In: Ciancio A., Mukerji K.G. (Eds.) General Concepts in Integrated Pest and Disease Management. Integrated Management of Plants Pests and Diseases, vol 1. Springer, Dordrecht

Edwards CA. 1980. Interactions between agricultural practice and earthworms. Soil biology as related to land use practice- Proc. VII. Int. Coll. Soil Zool., Syracuse, pp. 3-12.

Erb SL, Bourchier RS, Van Frankenhuyzen K, Smith SM. 2001. Sublethal effects of Bacillus thuringiensis Berliner subsp. kurstaki on Lymantria dispar (Lepidoptera: Lymantriidae) and the tachinid parasitoid Compsilura concinnata (Diptera: Tachinidae). Environ Entomol. 30(6): 1174-1181. https://doi. org/10.1603/0046-225X-30.6.1174

Georghiou GP. ed. 2012. 'Pest resistance to pesticides. Springer Science and Business Media.

Ghimire MN, Phillips TW. 2014. Oviposition and reproductive performance of Habrobracon hebetor (Hymenoptera: Braconidae) on six different pyralid host species. Ann Entomol Soc Am. 107(4): 809-817. https://doi.org/10.1603/AN14046
Godfray HCJ, Hunter MS. 1994. Heteronomous hyperparasitoids, sex ratios and adaptations: a reply. Ecol Entomol. 19(1): 93-95. https://doi. org/10.1111/j.1365-2311.1994.tb00397.x

Gunduz EA, Gulel A. 2005. Effects of adult age and host species on development period of parasitoid Bracon hebetor (Say) (Hym.: Braconidae). OMU Ziraat Fakulty Dergisi 20: 31-36.

Kangade YP. 2012. Study of biopesticides from local plants to control Corcyra cephalonica infestation in rice. $\mathrm{PhD}$ Thesis, Dr. Babasaheb Ambedkar Marathwada University.

Leora Software. 2005. POLO-Plus, POLO for Windows computer program, version 2.0. Petaluma.

Mahdavi V. 2013. Residual toxicity of some pesticides on the larval ectoparasitoid, Habrobracon hebetor Say (Hymenoptera: Braconidae). J Pl Prot Res. 53(1): 27-31. https://doi.org/10.2478/jppr-2013-0003

Mathew IL, Singh D, Singh RP, Tripathi CPM. 2014. Bacillus thuringiensis: The biocontrol agent in a food web perspective. Biolife 2(1): 348-362.

Mattiacci L, Dicke M. 1995a. Host age discrimination during host location by Cotesia glomerata, a larval parasitoid of Pieris brassicae. Entomol Exp Appl. 76(1): 37-48. https://doi.org/10.1111/j.1570-7458.1995.tb01944.x

Mattiacci L, Dicke M. 1995b. The parasitoid Cotesia glomerata (Hymenoptera: Braconidae) discriminates between first and fifth larval instars of its host Pieris brassicae, on the basis of contact cues from frass, silk, and herbivore-damaged leaf tissue. $J$ Insect Behav. 8(4): 485-498. https://doi.org/10.1007/BF01995321

Metcalf RL. 1994. Insecticides in pest management. pp.245- 284. In: Metcalf RL, Luckman WH (Eds.). Introduction to insect pest management, Vol. 3, Wiley, USA .

Murray TJ, Withers TM, Mansfield S. 2010. Choice versus no-choice test interpretation and the role of biology and behavior in parasitoid host specificity tests. Biol Control 52(2): 153-159. https://doi.org/10.1016/j.biocontrol.2009.10.003 
Nealis V, van Frankenhuyzen K. 1990. Interactions between Bacillus thuringiensis Berliner and Apanteles fumiferanae Vier.(Hymenoptera: Braconidae), a parasitoid of the spruce budworm, Choristoneura fumiferana (Clem.)(Lepidoptera: Tortricidae). Can Entomol. 122(4): 585-594. https://doi.org/10.4039/ Ent122585-7

Ode PJ, Antolin MF, Strand MR. 1997. Constrained oviposition and female-biased sex allocation in a parasitic wasp. Oecologia 109(4): 547-555. https://doi. org/10.1007/s004420050115 PMid:28307338

Oluwafemi AR, Rao Q, Wang XQ, Zhang HY. 2009. Effect of Bacillus thuringiensis on Habrobracon hebetor during combined biological control of Plodia interpunctella. Insect sci. 16(5): 409-416. https://doi. org/10.1111/j.1744-7917.2009.01262.x

Pimentel D. 1996. Green revolution agriculture and chemical hazards. Sci Total Environ. 188: S86-S98.

Ranga Rao GV, Rupela OP, Rao VR, Reddy YVR. 2007. Role of biopesticides in crop protection: present status and future prospects. Indian J Pl Prot. 35(1): 1-9.

Sait SM, Begon M, Thompson DJ, Harvey JA, Hails RS. 1997. Factors affecting host selection in an insect host-parasitoid interaction. Ecol Entomol. 22(2): 225-230. https://doi.org/10.1046/j.1365-2311.1997. t01-1-00051.x

Say T. 1836. Descriptions of new species of North American Hymenoptera, and observations on some already described. Boston Jour Nat Hist. 1(4): 734.

Singh D, Mathew IL. 2015. The Effect of Bacillus thuringiensis and Bt Transgenics on Parasitoids during Biological Control. Int J Pure App Biosci. 3(4): 123-131.

Singh D. 2004. Factors affecting age specific life table statistics of Bracon hebetor Say Hymenoptera: Braconidae. $\mathrm{PhD}$ thesis, Deen Dayal Upadhyay University, Gorakhpur.

Singh D, Mathew IL, Singh RP. 2009. Influence of different temperature regimes on Intrinsic rate of Increase ( $\mathrm{rm}$ ) of Bracon hebetor. Say (Hymenoptera: Braconidae) reared on Corcyra cephalonica. Stainton (Lepidoptera: Pyralidae). Jigyasa 2(2): 44-49.
Singh D. Mathew IL, Singh RP. 2014. Influence of different diets on intrinsic rate of natural increase (rm) of Bracon hebetor. say (hymenoptera: braconidae) reared on Corcyra cephalonica. stainton (lepidoptera: pyralidae). Biolife 3: 653-656. https://doi.org/10.17812/ blj.2015.3312

Singh, D., Singh, R.P. and Tripathi, C.P.M., 2016. Effect of host density on life table statistics of Bracon hebetor Say, 1836 (Hymenoptera: Braconidae). Trop Zool. 29(1), pp.44-51. https://doi.org/10.1080/03946975.20 16.1145399

Surgeoner GA, Farkas MJ. 1990. Review of Bacillus thuringiensis var. kurstaki (Btk) for use in forest pest management programs in Ontario, with special emphasis on the aquatic environment. Report prepared for: Aquatic Criteria Development Committee Water Resources Branch, Department of Environmental Biology University of Guelph Guelph, Ontario. 79 PP.

Ulpah S, Kok LT. 1996. Interrelationship of Bacillus thuringiensis Berliner to the diamondback moth (Lepidoptera: Noctuidae) and its primary parasitoid, Diadegma insulare (Hymenoptera: Ichneumonidae). J Entomol Sci. 31(4): 371-377. https://doi.org/10.18474/0749-800431.4 .371

Vail PV. Hoo CS, Seay RS, Killinen RG, Wolf WW. 1972. Microbial control of lepidopterous pests of fall lettuce in Arizona and effects of chemical and microbial pesticides on parasitoids. Environ Entomol. 1(6): 780-785. https://doi.org/10.1093/ee/1.6.780

Verma VC, Pathak PH. 2018. Effects of Azadirachta Indica leaf oil volatiles on immature stages of Corcyra cephalonica and characterization of active Ingredients by Gas Chromatography-Mass Spectrometry Int $J$ Engineering Technol Sci Res. 5(1): 100-106.

Wilby A, Thomas MB. 2002. Natural enemy diversity and pest control: patterns of pest emergence with agricultural intensification. Ecol Lett. 5(3): 353-360. https://doi.org/10.1046/j.1461-0248.2002.00331.x

Withers TM, Browne LB. 2004. Behavioral and physiological processes affecting outcomes of host range testing. pp. 40-45. In: Van Driesche R G, Reardon $\mathrm{R}$ (Eds.). Assessing host ranges for parasitoids and predators used for classical biological control: A guide to best practice. Morgantown, West Virginia. 
Wright DJ, Verkerk RH. 1995. Integration of chemical and biological control systems for arthropods: evaluation in a multitrophic context. Pest Manag Sci. 44(3): 207-218. https://doi.org/10.1002/ps.2780440302

Yu SH, Ryoo MI, Na JH, Choi WI. 2003. Effect of host density on egg dispersion and the sex ratio of progeny of Bracon hebetor (Hymenoptera: Braconidae). J Stored Prod Res. 39(4): 385-393. https://doi.org/10.1016/S0022-474X(02)00032-2
Yu YS. Shan X, WANG F, WU JC. 2008. Pest resurgence induced by pesticides [J]. Chinese Bull Entomol. 1: 011.

Zhang HY, Deng WX, Yu ZN. 1995. A review on the progresses of controlling stored product insects with Bacillus thuringiensis. Chinese J Biol Control 11: 178-182. 